\title{
Use of logbooks as a tool for life-long learning
}

\author{
Sylvie Doré \\ Mechanical Engineering \\ École de technologie supérieure
}

A new learning activity designed to raise awareness of students to lifelong learning was introduced in an elective course in mechanical engineering at École de technologie supérieure. The goal of the paper is to describe this activity and to report on its effectiveness.

Additive manufacturing (or rapid prototyping as is used to be known) is a rapidly evolving set of technologies. Because factual knowledge regarding additive manufacturing becomes rapidly obsolete, the course Rapid Prototyping is aimed not so much at learning the different additive manufacturing processes but rather on developing methodological skills by which students will be able to maintain their knowledge up to date. In this sense, the course is already oriented towards lifelong learning.

In the fall of 2012, a new activity designed specifically to foster lifelong learning was introduced. As a first step, students were asked to fill out a logbook on a weekly basis to note the following information: numbers of hours spent in and out of class on the course and most significant knowledge acquired or developed during the week. At the end of a semester, students were asked to write a 2 to 3 page report describing: 1) the most significant knowledge, know-how and social/behavioral skills acquired or developed during the course; 2) gaps in their knowledge, know-how and social/behavioral skills; 3 ) strategies and identify resources to fill these gaps.

In a class of 29, all students except two handed in the report. All students were able to describe new knowledge, most were able to identify new know-how and only a few students wrote about social/behavioral skills. Most students were able to identify gaps in their knowledge, know-how or skills. Many of them referred to strategies and resources to which they had been exposed during the course but which they had not necessarily devoted enough time to explore thoroughly as means of filling the gaps. This information is also valuable as a source of course improvement and is much richer than traditional course evaluations. The activity, although still needing refinement, is deemed worthy of being pursued. Furthermore, it is sufficiently generic that it can easily be adapted to other courses. 